\title{
A study of selected biomechanical variables as a factor of hitting performance among softball players
}

\author{
Pushkar Yadav \\ PGT (physical education) Delhi public school, Bahadurgarh (HR) India
}

\begin{abstract}
The modern age of sports is the excellence, so in every sports perfection and purification of skill has got its immense importance. Biomechanics is an applied form of mechanics and consequently the method used to investigate it must be derived from those of mechanics. Biomechanics aim to explain the mechanics of life. Sports biomechanics have also generated other efforts at improving athletic performance in different games and sports; it is helpful to minimize sports injuries through both identifying dangerous practice and designing safer equipment and apparel. The purpose of this study was to investigate the relationship of selected biomechanical variables with the hitting performance in softball.
\end{abstract}

Keywords: Biomechanical Variable, Centre of gravity, Evaluation of technique, Performance, Softball Hitting.

\section{Introduction}

Among the animals man has been the successful in the constant struggle with the environment. Even though he cannot run as fast as quadriceps, swim like dolphin, climb like monkeys, fly like birds; he has been the only creature able to defy the forces of gravity and move into outer space. Nowadays, sports has become an important part of our life. Millions of fans follow different sports events over the world with an enthusiasm. New techniques develop as a result of scientific analysis only. Scientific study helps to identify the economy of techniques for better results. For instance, in the high jump, there are no less than six named styles (scissors, modified scissors or back layout, eastern cut off, western roll, straddle roll and fosbury flop).

The purpose of study was to analyse the relationship of selected kinematic variables with performance of subjects in softball hitting. The subjects for study were 5 softball players of All India inter varsity level. The study was delimited to the following biomechanical variable:

- $\quad$ Angular kinematic variable (angle at joints)

- $\quad$ Ht of centre of gravity at the time of stance

- $\quad$ Ht of centre of gravity at the time of contact of ball/swing (Execution)

The digital camera (Nikon D-100) was employed to register the technique of batting at selected moments. The subjects were photographed at the moment of stance and execution of swing in sagittal plane. From the photographic sequence, the stick figures were prepared by using joint point method. The angles and centre of gravity were calculated at selected moments. In order to find out the relationship of selected kinematic variables and the performance of subjects in softball hitting, the Pearson's product moment correlation was calculated. The level of significance was 0.05 .

A study of relevant literature was an essential step to get a full picture of what has been done with regard to the problem under the study. Related research work :

Effects of bat grip on baseball hitting kinematics ${ }^{[1]}$. Bat speed, trajectory, and timing for collegiate baseball batters hitting a stationary ball ${ }^{[2]}$. Numerical analysis of maximal bat performance in baseball ${ }^{[3]}$. Hitting a baseball: biomechanical description ${ }^{[4]}$. Pelvis, torso kinematics and their relationship to shoulder kinematics in high-school baseball pitchers ${ }^{[5]}$.

\section{Methodology}

Five male softball players of L.N.U.P.E., Gwalior from the softball match practice group were selected as the subject for the present study; these players represented the university in ALL INDIA CHAMPIONSHIP. There age was between 19 to 23 years. The performance of each subject on batter's plate for hitting ability was collected on the basis of softball team skill assessment test (SAT) Fig.1 by ranking player's hitting ability on a 5 point rating scale. The batter assumes a normal batting stance at the plate. From the pitcher's mound, a pitcher threw five hittable pitches that the batter attempts to hit as hard as possible, selecting the pitch. Only five swings were allowed to each batter. The total of all the successful hits was considered as final score.

\section{Experimental Filming Protocol}

The performance of each subject on batter's plate for hitting ability was collected on the basis of softball team skill assessment test (SAT). The total of all the successful hits was considered as final score. The 
recording was determined on outdoor softball ground. The total area available for hitting purpose was 240 feet including the diamond. The batter was asked to hit the ball being pitched from pitcher's plate 46 feet away. The video camera was placed on tripod stand in saggital plane at an distance of 15 feet from batter. The filming zone was set up at 20 feet within which recording were to be taken. After video recording final position of each selected phase was obtained on the screen by trial and error method and kept in pause. Further the Elgon of each phase i.e. the hitting stance converted in photographs and drawn on transparency by the joint point method for all selected subjects. The centre of the gravity of each body segment and the whole body was determined by segmentation method as suggested by James $\mathrm{G} \mathrm{Hay}^{[6]}$. The angle at various joints was determined by this method.

\section{Figures And Tables}

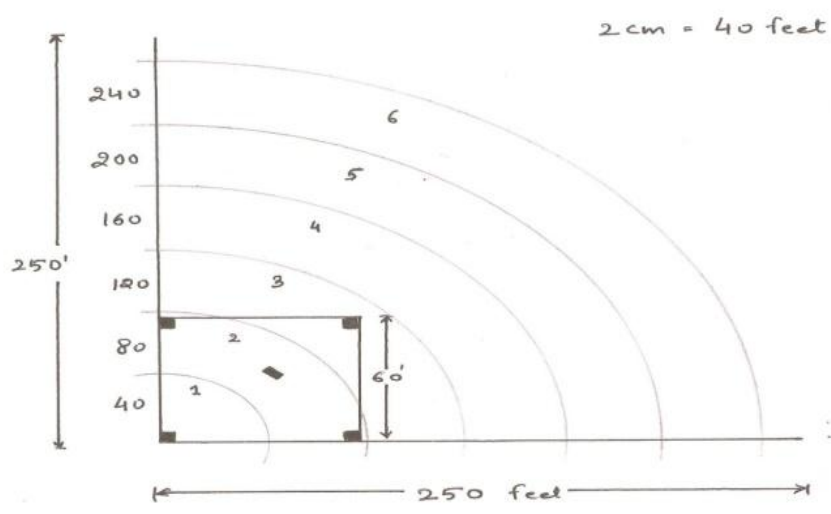

Figure 1 Softball Skill Assesment Test

Table 1 Relationship Of Selected Angular Kinematic Variables At Batting Stance With Performance Of Subjects In Hitting.

\begin{tabular}{lll}
\hline \hline S.NO & VARIABLES & Coefficient of correlation \\
\hline $\mathbf{1 .}$ & Shoulder joint right & .470 \\
$\mathbf{2 .}$ & Shoulder joint left & .285 \\
$\mathbf{3 .}$ & Elbow joint right & .048 \\
$\mathbf{4 .}$ & Elbow joint left & .137 \\
$\mathbf{5 .}$ & Wrist joint right & -.010 \\
$\mathbf{6 .}$ & Wrist joint left & .266 \\
$\mathbf{7 .}$ & Hip joint right & -.382 \\
$\mathbf{8 .}$ & Hip joint left & -.570 \\
$\mathbf{9 .}$ & Knee joint right & -.420 \\
$\mathbf{1 0}$ & Knee joint left & -.342 \\
\hline
\end{tabular}

Since the value of coefficient of correlation required to be significant for 3 degree of freedom is .878 , the above table clearly shows that in case of shoulder joint (right and left), elbow joint (right and left), wrist joint (right and left), hip joint (right and left), knee joint (right and left) is lesser than table value therefore it have no significant relationship with performance of subjects in softball hitting. 
Table 2 Relationship Of Selected Angular Kinematic Variables At Batting Execution With Performance Of Subjects In Hitting.

\begin{tabular}{lll}
\hline \hline S.NO & VARIABLES & Coefficient of correlation \\
\hline $\mathbf{1 .}$ & Shoulder joint right & -.732 \\
$\mathbf{2 .}$ & Shoulder joint left & -.672 \\
$\mathbf{3 .}$ & Elbow joint right & $-.894 *$ \\
$\mathbf{4 .}$ & Elbow joint left & -.562 \\
$\mathbf{5 .}$ & Wrist joint right & .603 \\
$\mathbf{6 .}$ & Wrist joint left & .066 \\
$\mathbf{7 .}$ & Hip joint right & .845 \\
$\mathbf{8 .}$ & Hip joint left & -.356 \\
$\mathbf{9 .}$ & Knee joint right & -.578 \\
$\mathbf{1 0 .}$ & Knee joint left & .387 \\
\hline
\end{tabular}

*Significant at 0.05 level

Since the value of coefficient of correlation required to be significant for 3 degree of freedom is .878 , the above table clearly shows that in case of shoulder joint (right and left), elbow joint (right and left), wrist joint (right and left), hip joint (right and left), knee joint (right and left) is lesser than table value therefore it have no significant relationship with performance of subjects in softball hitting whereas correlation value is higher in case of elbow joint (right) indicating significant negative relationship with performance.

Table 3_Relationship Of Linear Kinematic Variables With The Performance Of Subjects At Batting Stance

\begin{tabular}{lll}
\hline \hline S. NO & VARIABLES & Coefficient of correlation \\
\hline $\mathbf{1 .}$ & Height of C.G. (stance) & .164 \\
$\mathbf{2 .}$ & Height of C.G. (execution) & .519 \\
\hline
\end{tabular}

Since the value of coefficient of correlation was required to be significant for 3 degree of freedom is .878 , the result of table shows that height of C.G at selected moments has insignificant relationship with performance of subjects in softball hitting.

\section{Conclusion}

Significant correlation was found only in case of one angular kinematic variable during swing of bat (execution) at elbow joint (right). Based on the analysis and within the limitation of present study we draw the conclusion that the right elbow joint have negative relationship with subject's hitting performance while swing of bat (execution). This indicated that angle at right elbow joint during swing can play an important role in hitting performance. In other words more is the angle at right elbow joint i.e. straightening of arm, better is the performance. The present study may contribute in following way:-

- Helpful to the physical education teacher, coaches and players to evaluate hitting performance.

- Help coaches to identify technical faults while teaching hitting technique to fresher.

- A mathematical model of hitting may be drawn on the basis of this study.

- This study may be under taken to analyse others elements in gymnastics and other games and sports.

\section{Journal Papers:}

\section{References}

[1]. Escamilla RF ${ }^{1}$, Fleisig GS, DeRenne C, Taylor MK, Moorman CT 3rd, Imamura R, Barakatt E, Andrews JR, Effects of bat grip on baseball hitting kinematics, Journal of Applied Biomechanics, 25(3), 2009, 203-9.

[2]. Tabuchi $\mathrm{N}^{1}$, Matsuo T, Hashizume K., Bat speed, trajectory, and timing for collegiate baseball batters hitting a stationary ball, Sports Biomechanics/International society of biomechanics in sports, 6(1), 2007, 17-30

[3]. Rochelle L. Nicholls, Karol Miller, Bruce C. Elliott, Numerical analysis of maximal bat performance in baseball, Journal of Biomechanics Vol. 39, Issue 6, 2006, 1001-1009

[4]. Welch $\mathrm{CM}^{1}$, Banks SA, Cook FF, Draovitch P, Hitting a baseball: biomechanical description, The Journal of Orthopaedic and Sports Physical Therapy, 22(5), Nov 1995,193-201

[5]. Oliver GD ${ }^{1}$, Keeley DW, Pelvis and torso kinematics and their relationship to shoulder kinematics in high-school baseball pitchers, Journal of strength and conditioning research, 24(12), 2010.

\section{Books:}

[6]. James G. Hay, The Biomechanics of Sports Techniques (4th Edition) (The University of Michigan, Prentice-Hall, 1993) 